\title{
DEVELOPMENT OF HIGH PERFORMANCE FERROELECTRIC MATERIAL FOR CAPACITOR AND ACTUATOR APPLICATIONS
}

\author{
M. V. Takarkhede ${ }^{1}$, S. A. Band ${ }^{2}$ \\ ${ }^{I}$ Department of Physics, JDCOEM, Nagpur, Maharashtra, India \\ ${ }^{2}$ Department of Physics, YCCE, Nagpur, Maharashtra, India
}

\begin{abstract}
A ternary system of composition 0.7PMN-0.2PT-0.1PZN and 0.7PMN-0.1PT-0.2PZN were investigated employing columbite route. A detailed and systematic study of phase, dielectric properties and microstructure were carried out and compared. Ceramics of composition 0.7PMN-0.1PT-0.2PZN demonstrated larger grain size and higher density than ceramics of composition 0.7PMN-0.2PT-0.1PZN. The composition 0.7PMN-0.1PT-0.2PZN exhibited enhanced dielectric properties in the sintering temperature 1100-1170 ${ }^{\circ} \mathrm{C}$ while composition 0.7PMN-0.2PT-0.1PZN exhibited enhanced dielectric properties in the sintering temperature range 1170-1180 C. Dielectric properties seem to be dependent on density and intrinsic dielectric constant of PMN, PZN for single phase perovskite ceramic. The ceramic of composition 0.7PMN-0.1PT-0.2PZN proved to be the best composition showing enhanced dielectric properties at lower sintering temperature as compared to 0.7PMN-0.2PT-0.1PZN.
\end{abstract}

Keywords: Ferroelectric, Capacitor, Actuator.

\section{INTRODUCTION}

The development of electronic devices such as sensors, actuators and capacitors require materials with desired crystal structure and excellent electromechanical properties as well as reliable processing route. The solid solution of lead titanate $\mathrm{PbTiO}_{3}(\mathrm{PT})$, lead magnesium niobate $\mathrm{Pb}\left(\mathrm{Mg}_{1 / 3} \mathrm{Nb}_{2 / 3}\right) \mathrm{O}_{3}(\mathrm{PMN})$ and lead zinc niobate $\mathrm{Pb}\left(\mathrm{Zn}_{1 / 3}\right.$ $\left.\mathrm{Nb}_{2 / 3}\right) \mathrm{O}_{3}(\mathrm{PZN})$, have attracted considerable attention as potential candidates for applications such as multilayer capacitors(MLC), actuators, and medical ultrasonic transducers during the last decade due to its high dielectric constant and high electrostrictive strain response[1,2].

It is very difficult to obtain a pure perovskite phase in PMN ceramics without secondary pyrochlore phase $[3,4]$. The pyrochlore phase is thermodynamically more stable and kinetically more favourable than the perovskite phase but functionally undesirable because it impairs the dielectric properties of the materials [5]. Previous studies reported that perovskite phase get stabilized by forming solid solution of PMN with PZN or PMN with PT or PMN with PZN and PT. The formation of solid solution increases the tolerance factor and electro negativity difference leading to stabilization of perovskite structure and enhancement of dielectric properties of ferroelectrics [6,7].

Very few studies were reported on ternary system of PMN, PZN and PT[8-14]. Therefore ternary solid solutions have been investigated to know the development of stabilization of perovskite phase and modulation of dielectric properties in terms of dielectric constant, Curie temperature and losses in the Curie range and degree of diffuseness. Numerous attempts have been made so far to develop a processing technique in which the formation of undesired pyrochlore is suppressed. Among the several methods reported in the literature Swartz route [15] proved to be the simple and most reliable in the synthesis of lead based ceramics to get reproducible dielectric properties.

Current study focuses on dielectric characterization of ceramics of ternary compositions $0.7 \mathrm{PMN}-0.2 \mathrm{PT}-0.1 \mathrm{PZN}$ and $0.7 \mathrm{PMN}-0.1 \mathrm{PT}-0.2 \mathrm{PZN}$ synthesized by columbite route. From the comparison of dielectric properties the best composition can be identified for possible applications in MLCs and actuators.

\section{EXPERIMENTAL}

In the present study ceramic of composition 0.7PMN-0.2PT$0.1 \mathrm{PZN}$ and $0.7 \mathrm{PMN}-0.1 \mathrm{PT}-0.2 \mathrm{PZN}$ is synthesized by Swartz's suggested double calcination route. $\mathrm{PbO}(99.9 \%$ Sigma), $\mathrm{MgO}$ (99.9\% Sigma) and $\mathrm{Nb}_{2} \mathrm{O}_{5}$ ( $99.99 \%$ Sigma), $\mathrm{ZnO}$ (99.999\% Sigma ), $\mathrm{TiO}_{2}(99.99 \%$ Sigma) were used as raw materials. The columbite lead magnesium niobate designated as $\mathrm{MN}$ is synthesized by mixing of 1.02 mole \% $\mathrm{MgO}$ and 1 mole of $\mathrm{Nb}_{2} \mathrm{O}_{5}$ and wolframite lead zinc niobate designated as $\mathrm{ZN}$ is synthesized by mixing of 1 mole $\%$ $\mathrm{ZnO}$ and 1 mole of $\mathrm{Nb}_{2} \mathrm{O}_{5}$. The dried $\mathrm{MN}, \mathrm{ZN}, \mathrm{PbO}$ and $\mathrm{TiO}_{2}$ were weighed according to stoichiometric formula required for the composition and ground well with acetone. The homogeneous mass is then calcined in an alumina crucible covered with lid at calcination temperatures $800^{\circ} \mathrm{C}$. To this homogeneous calcined powder polyvinyl acetate is added as a binder and pellets $1-2 \mathrm{~mm}$ thickness and $1 \mathrm{~cm}$ diameter is then formed by applying uniaxial pressure (1 ton $/ \mathrm{cm}^{2}$ )in a stainless steel die. The pellets were sintered in closed alumina crucible at temperatures between 1100$1180^{\circ} \mathrm{C}$ for $2 \mathrm{hrs}$. The heating rate kept during calcination and sintering was $10^{\circ} \mathrm{C}$ per/min. as optimized in previous study [16]. During the sintering the pellets were covered 
with the powder of the same composition to minimize the $\mathrm{PbO}$ losses. The detailed flow chart of synthesis is given in Fig 1.

XRD of sintered ceramics was carried out at room temperature (Siemens D500 diffractometer, using $\mathrm{CuK} \alpha$ radiation over angular range $2 \theta$ between 10 to $100^{\circ}$ by step of $0.02^{\circ}$ ). XRD patterns were used to identify the structure formed and to know the relative content of the perovskite phase. The microstructure analysis was carried out using a scanning electron microscopy analyzer (SEM, JEOLJSM84A0). Grain size of the sintered ceramics was estimated from the microstructural using linear intercept method. Densities of the sintered specimens were measured by Archimedes water displacement method. For electrical measurements the surfaces of the sintered ceramic were polished using silicon carbide sand paper (220, 400 grit) to produce parallel smooth surfaces. Silver paste was coated on both the surfaces of the well-polished ceramics and fired at $550^{\circ} \mathrm{C}$ for $30 \mathrm{~min}$. to provide robust electrode. Dielectric measurements ( $\varepsilon$ and $\tan \delta$ ) were made using impedance analyzer(Model 4192A Hewlett Packard LF impedence analyzer) in the frequency range $100 \mathrm{~Hz}-100 \mathrm{kHz}$ between $30^{\circ} \mathrm{C}$ to $170^{\circ} \mathrm{C}$. The dc resistivity is measured at room temperature (RT) using picoammeter (Model DPA111). Current values are measured 2 minutes after application of voltage $=30 \mathrm{~V}$. The characteristics and dielectric properties of the sintered ceramic were demonstrated in terms of second phase, grain size and density.

The electrical resistivity of ceramics is greater than $10^{11} \Omega$ $\mathrm{cm}$ similar to previous report [24]. Fig.4 show the graphs of dielectric constant and the loss tangent Vs temperature respectively of ceramics PMZNT4 and PMZNT8 at four different frequencies $100 \mathrm{~Hz}, 1 \mathrm{kHz}, 10 \mathrm{kHz}, 100 \mathrm{kHz}$ in the temperature range $30-170^{\circ} \mathrm{C}$. The peak of dielectric constant is broad and decreases in magnitude as the frequency increases is seen in all samples. Further it is observed that $\varepsilon_{\max }$ shifts towards higher temperature as the frequency increases and the temperature of $\tan \delta_{\max }$ as well as $\tan \delta_{\max }$ increases with frequency thus both the compositions demonstrated the typical relaxor behaviour.

In majority of the samples the transition temperature shifts to the lower side with increase in sintering temperature is observed. Further the shift in Tc with frequency from $100 \mathrm{~Hz}$ to $100 \mathrm{kHz}$ for composition $0.7 \mathrm{PMN}-0.2 \mathrm{PT}-0.1 \mathrm{PZN}$ is between 4-5 and for composition 0.7PMN-0.1PT-0.2PZN it is between 7-9 is observed. This reflect lower dielectric relaxation in case of samples with higher concentration of PT similar to reported earlier $[19,25,26]$. This is attributed to higher concentration $\mathrm{Ti}$ which decreases the $\mathrm{B}$-site order similar to previous reports $[1,25,27]$.

\section{RESULT AND DISCUSSION}

The ceramics synthesized of composition 0.7PMN-0.2PT$0.1 \mathrm{PZN}$ and $0.7 \mathrm{PMN}-0.1 \mathrm{PT}-0.2 \mathrm{PZN}$ are designated as reported in Table 1 .The dielectric properties $\left(\varepsilon_{\max }, \mathrm{Tc}, \tan \delta\right.$ at Tc) and other physical properties such as $\%$ of perovskite phase, lattice constant ' $a$ ', grain size, relative density ' $D$ ', $\Delta \mathrm{Tc}$ (Difference in Tc's from $100 \mathrm{~Hz}$ to $100 \mathrm{kHz}$ ), diffuseness coefficient ' $\delta$ ' and electrical resistivity ' $\rho$ ' of sintered ceramics are summarized in Table- 2 .

The XRD patterns of all ceramics (PMZNT1- PMZNT8) are presented in Fig.2. In all the samples PMZNT1- PMZNT8, all the peaks correspond to pseudo cubic perovskite phase (JCPDS 27-1199) and no peaks corresponding to pyrochlore appear which confirms the formation of single phase perovskite. No significant change in the lattice constant is observed.

The Scanning electron micrographs of the sintered ceramics are presented in Fig.3. All the ceramics exhibit similar microstructure except the variation in grain size and pore formation. The microstructure reveals increase in grain size and decrease in pore formation with increase in sintering temperature similar to reported by previous authors [17-19]. For composition 0.7PMN-0.2PT-0.1PZN little agglomeration of grains is seen at all temperatures. Also 0.7PMN-0.2PT-0.1PZN exhibited relatively lower grain size than $0.7 \mathrm{PMN}-0.1 \mathrm{PT}-0.2 \mathrm{PZN}$ at the same sintering conditions. The relative density of the samples is found to be increased with increase in sintering temperature except sample PMZN8, no change in density is observed. Further the density of ceramics PMZNT1-PMZNT4 is lower than PMZNT5-PMZNT8 at same sintering conditions. This seems to be due to larger content of $\mathrm{Zn}$, the densification occurs at lower temperature [20-23].

The quadratic law (Eq 2) has been further used to analyse the relaxor behaviour of synthesized ceramics

$$
\frac{1}{s}=\frac{1}{s_{m}}+\frac{T-T_{c}^{2}}{2 s_{m} \delta^{2}}
$$

Where $\delta$ is called diffuseness parameter which is a measure of the diffuseness of transition.

The graphs of $1 / \mathcal{E} \mathrm{Vs}[\mathrm{T}-\mathrm{Tc}]^{2}$ is shown in Fig.-5. The straight line graph demonstrates ceramics exhibit relaxor behaviour. The diffuseness parameter obtained from the graph for all samples are reported in Table2. It is observed $\delta$ decreases as the sintering temperature increases in both the compositions $[11,12,19,28]$.

In composition 0.7PMN-0.1PT-0.2PZN which contains more $\mathrm{Zn}$ exhibit larger dielectric values at lower sintering temperature due to higher density achieved. As the sintering temperature exceeds $1150^{\circ} \mathrm{C}$, the saturation of dielectric permittivity is observed. However the composition 0.7PMN0.2PT-0.1PZN which contains larger content of Ti exhibit relatively low dielectric values at lower sintering temperature up to $1150^{\circ} \mathrm{C}$ due to lower density values attained. But when the temperature approaches $1170^{\circ} \mathrm{C}$ the density gets increased rapidly and dielectric values get increased significantly. In these compositions the dominant effect of $\mathrm{ZN}$ is observed at lower sintering temperature 
upto $1150^{\circ} \mathrm{C}$ and dominant effect of PT is observed at higher sintering temperature after $1150^{\circ} \mathrm{C}$.

The high value of $\varepsilon_{\mathrm{max}} \approx 21000-25000$ with $\mathrm{Tc}=72^{\circ} \mathrm{C}$ and $\approx 15000-17000$ with $\mathrm{Tc}=115-113^{\circ} \mathrm{C}$ are obtained for composition 0.7PMN-0.1PT-0.2PZN and 0.7PMN-0.2PT$0.1 \mathrm{PZN}$ at sintering temperature range 1100 and $1150^{\circ} \mathrm{C}$ respectively. These obtained values are higher than reported in the study of Wang et al [14]. This result reflect the composition 0.7PMN-0.1PT-0.2PZN demonstrate the superior dielectric properties with $\mathrm{Tc}$ near RT at lower sintering temperature and proved to be the best composition for use in MLCs and actuators.

The highest value of $\varepsilon_{\max }$ at $100 \mathrm{~Hz}$ is obtained for the composition $0.7 \mathrm{PMN}-0.2 \mathrm{PT}-0.1 \mathrm{PZN}$ at sintering temperature $1180^{\circ} \mathrm{C}=33409$ and $\mathrm{Tc}=105^{\circ} \mathrm{C}$ for which $95 \%$ of the density is reached. This value is much higher than previously reported values $[8,12,14]$.

The highest value of $\varepsilon_{\max }$ obtained for ceramic PMZN4 $\left(\varepsilon_{\max }=33409\right)$ and PMZN8 $\left(\varepsilon_{\max }=29910\right)$ reflect the dielectric properties are found to be strongly dependent on density and the grain size. Higher density is achieved at higher sintering temperature as higher temperature provides greater thermal activation energy for grain growth and elimination of pores thereby favours more effective sintering process. As the grain size increases the number of grain boundaries in series with perovskite grains decreases and dielectric constant increases [7,29,30,31].

\section{CONCLUSION}

Higher density is obtained for composition with higher $\mathrm{Zn}$ content at lower sintering temperature. Ceramic with composition 0.7PMN-0.2PT-0.1PZN containing more Ti content exhibit smaller grains and lower densities than ceramics with composition 0.7PMN-0.1PT-0.2PZN containing more $\mathrm{Zn}$ content. Further lower dielectric relaxation is obtained for composition 0.7PMN-0.2PT0.1PZN than composition 0.7PMN-0.1PT-0.2 PZN.

The ternary system with more PT shows enhanced dielectric values at higher sintering temperature $1170-1180^{\circ} \mathrm{C}$, however the composition with more $\mathrm{Zn}$ shows enhanced dielectric values at lower sintering temperature. The compositions reflect the dominant effect of PT and $\mathrm{Zn}$ at higher and lower sintering temperature $1100-1170^{\circ} \mathrm{C}$ respectively.

0.7PMN-0.1PT-0.2PZN composition proved to be the best composition demonstrating higher dielectric properties at lower sintering temperature with Tc close to RT and most suited for commercial applications in MLCs and actuators.

\section{REFERENCES}

[1]. Guisheng XU, Haosu LUO, Wang Pingchu, Zhenyi QI , Zhiwen YIN; "Ferroelectric Phase transition in relaxor ferroelectric single crystals 0.76PMN-0.24 PT"; Chineese, Science Bulletin; Vol.45, No. 15;(Aug 2000) pp. 1380-1385. [2]. Zhu X.Tan Y, Wang Q., Cai Z., Meng Z.; "Dielectric and electrostrictive properties of $\mathrm{Pb}\left(\mathrm{Zn}_{1 / 3} \quad \mathrm{Nb}_{2 / 3}\right) \mathrm{O}_{3}-\mathrm{Pb}$ $\left(\mathrm{Mg}_{1 / 3} \mathrm{Nb}_{2 / 3}\right) \mathrm{O}_{3}-\mathrm{PbTiO}_{3}$ ceramic solid solution.”; Japn J App. phys; vol. 33;(1994) ;pp. 6623-6625.

[3]. Lejuene M.,Boilot J.P.;"Formation mechanism and ceramic process of ferroelectric perovskites: $\mathrm{Pb}\left(\mathrm{Mg}_{1 / 3}\right.$

$\left.\mathrm{Nb}_{2 / 3}\right) \mathrm{O}_{3}$ andPb $\left(\mathrm{Fe}_{1 / 2} \mathrm{Nb}_{1 / 2}\right) \mathrm{O}_{3}$."; Ceramics International; Vol.8[3];(1982) pp.99-103.

[4]. Guha J. P., Anderson H.U.;"Preparation of perovskite $\mathrm{Pb}\left(\mathrm{Mg}_{1 / 3} \mathrm{Nb}_{2 / 3}\right) \mathrm{O}_{3}$ using $\mathrm{Pb}_{3} \mathrm{Nb}_{2} \mathrm{O}_{8}$ and $\mathrm{MgO}$ "; J. Am. Ceram. Soc.; Vol. 69 [11];(1986); pp. C- 287-C-288.

[5]. Zhai Hai fa, Tang Rong -Lu, Li Ai-Dong, Guo HaiRong, Xia Yi-Dong, Wu Di; "Preparation and

characterization of relaxor ferroelectric $0.65 \mathrm{~Pb}\left(\mathrm{Mg}_{1 / 3} \mathrm{Nb}_{2 / 3}\right) \mathrm{O}_{3}-0.35 \mathrm{PbTiO}_{3}$-by a Polymerizable complex method.”; J. Am. Ceram. Soc.; Vol. 92[6]; (2009); pp. 1256-1261.

[6]. Randall C. A., Bhalla A. S., Shrout T. R., Cross L. E.; "Classification and consequences of complex lead perovskite ferroelectrics with regard to B- site cation order"; J. Mater. Res.;Vol.5[4];(1990); pp. 829-843.

[7]. Ding Chenlu, Fang Bijun, Du Qingbo, Zhou Limin; "Phase structure and electrical properties of $0.8 \mathrm{~Pb}\left(\mathrm{Mg}_{1 / 3} \mathrm{Nb}_{2 / 3}\right) 0_{3}-0.2 \mathrm{PbTiO}_{3}$ relaxor ferroelecric ceramics prepared by Reaction -sintering method"; Phys. Status Solidi A; Vol.209;(2010); pp. 979-985.

[8]. Lee S. H., Kim K. C., Kim Y. J., Choi S. W.; "Dielectric, Pyroelectric and Piezoelectric properties in the $\mathrm{Pb}\left(\mathrm{Mg}_{1 / 3} \mathrm{Nb}{ }_{2 / 3}\right) \mathrm{O}_{3}-\mathrm{PbTiO}_{3}-\mathrm{Pb}\left(\mathrm{Zn}_{1 / 3} \mathrm{Nb}_{2 / 3}\right) \mathrm{O}_{3}$ system"; Conference.: Application of ferroelectrics 1992 ISAF 92Date of conference 30Aug -02 sep 1992; 3080-0-78030465-9/95 IEEE, Published in Proceedings of the eight IEEE International symposium;(1992); pp. 588-591.

[9]. Gui Z., Li L., Zhang X.;"Study on dielectric properties of PMN-PZN-PT ferroelectric relaxor ceramics"; proceedings of $3^{\text {rd }}$ international conference on properties and applications of Dielectric materials July 8-12, Tokyo Japan;(1991); pp. 816-819.

[10]. Sharma S.,Sati R.,Choudhary N. P., Sinha T. P; "Diffuse phase transition in solid solution $\mathrm{Pb}\left(\mathrm{Mg}_{1 / 4} \mathrm{Zn}_{1 / 4}\right.$ $\left.\mathrm{Nb}_{1 / 2}\right) \mathrm{O}_{3-\delta}$ and $\mathrm{PbTiO}_{3}$."; Material letters; Vol. 16; (1993); pp. 281-285.

[11]. Choi S. W., Kim Y. J., Weon H. Y., Shin Y. H.; "Dielectric, Piezoelectric and Pyroelectric properties in the $(1-\mathrm{x}) \mathrm{Pb}\left(\mathrm{Mg} \quad{ }_{0.7} \mathrm{Zn}_{0.3}\right)_{1 / 3} \mathrm{Nb}_{2 / 3} \quad \mathrm{O}_{3} \quad$ - x $\mathrm{PbTiO}_{3}$ system"; Ferroelectrics; Vol. 158; (1994); pp. 247-252.

[12]. Xie Zhipeng, Giu Zhilun, Li Longoto,Huang Xiangdong, Haung Yong; "Characterization of lead based relaxor ferroelectric ceramics sintered in a $2.45 \mathrm{GHz}$ microwave radiation"; Journal of Material science ;Vol. 35;(2000); pp. 203-207.

[13]. Escure P., Lattard E., Lejeune M.,Baumard J. F.; "Stability of the perovskite phase in PMN-PZN-PT ceramics"; Journal of Material Science ; Vol. 31;(1996); pp. 3937-3943.

[14]. Wang J., Wan D., Xue J.; "Mechano chemical 
fabrication of electroceramics" ; Patent No US 6627, 104B1 (2003)

[15]. Swartz S. L.,Shrout T.; "Fabrication of perovskite lead magnesium niobate"; Mat. Res. Bull.; Vol. 17;(1982); pp.1245-1251.

[16]. Liou Yi. Cheng, Wu Long; "Effect of heating rate on the dielectric properties of PMN-PT relaxor ceramics"; J. Am. Ceram. Soc.; Vol.77[12]; (1994); pp. 3255-3258.

[17]. Shrout T. R.,Halliyal A.;"Preparation of lead based ferroelectric relaxors for capacitors"; Am. Ceram. Soc. Bull.; Vol. 66; (1987); pp. 704-711.

[18]. Ravindranathan P., Komarneni S.,Bhalla A., Roy R.; "Synthesis and dielectric properties of solution sol gel derived 0.9PMN-0.1PT ceramics"; J. Am. Cerm. Soc.; Vol.74 [11] ;(1987); pp. 2996-2999.

[19]. Wongmaneerung R., Yimnirun R., Ananta S. "Fabrication and characterization of perovskite ferroelectric PMN/PT ceramic nano composites"; J. Mater. Sci.; Vol. 44; (2009); pp.5428-5440.

[20]. Yoon Ki Hyun, Ahn Ki Pyung, Cho Yong Soo,;"Effect of $\mathrm{ZnO}$ on dielectric properties of $\mathrm{Pb}\left(\mathrm{Mg}_{1 / 3} \mathrm{Nb}_{2 / 3}\right) \mathrm{O}_{3}$ $\mathrm{PbTiO}_{3}$ ”; Ferroelectrics; Vol.146;(1993); pp. 57-64.

[21]. Lee T., Lee Jo-Young, Kim Bok-Hee;"Synthesis of $0.8 \mathrm{PMN}-0.2 \mathrm{PZN}$ perovskite phase by an emulsion method and its dielectric properties."; Journal of Ceramic Processing Research; Vol. 12, No. 6;(2011); pp. 630-633.

[22]. Steven M., Landin, Schedule Walter A.;"Rapid sintering of stoichiometric Zinc-Modified Lead Magnesium Niobate"; J. Am. Ceram. Soc.; Vol. 73[4];(1990); pp. 913917.

[23]. ChaeMin-Chul,Kim Nam-Kyqung, Kim Jeong-Joo, Cho Sang-Hee, "Preparation of $\mathrm{Pb}\left(\mathrm{Mg}_{1 / 3} \mathrm{Nb}_{2 / 3}\right) \mathrm{O}_{3}$ $\mathrm{Pb}\left(\mathrm{Zn}_{1 / 3} \mathrm{Nb}_{2 / 3}\right) \mathrm{O}_{3}$ ceramics by $\mathrm{B}$-site precursor method and dielectric characteristics"; Journal of Materials Sciences; Vol. 33;(1998); pp.1343-1348.

[24]. Lejenue M., Biolot J. P. ;"Low firing dielectrics based on lead magnesium niobate"; Mat. Res. Bull.;Vol.20;(1985); pp. 493-499.

[25]. Elissalde C., Ravez J., Gaucher P., "Dielectric Relaxsation in ceramics with composition (1$\mathrm{x}) \mathrm{Pb}\left(\mathrm{Mg}_{1 / 3} \mathrm{Nb}_{2 / 3}\right) \mathrm{O}_{3}-\mathrm{x} \quad \mathrm{PbTiO}_{3}(\mathrm{x}=0.05,0.10$, and 0.25$)$ "; Material Sci. and Engineering; (1993); pp. 303-309.

[26]. Halliyal A., Kumar U., Newnham R. E., Cross L. E.; "Dielectric and ferroelectric properties of ceramics in the $\mathrm{Pb}$ $\left(\mathrm{Zn}_{1 / 3} \quad \mathrm{Nb}_{2 / 3}\right) \mathrm{O}_{3}-\mathrm{BaTiO}_{3}-\mathrm{PbTiO}_{3}$ system"; J. Am. Ceram.Soc.; Vol 70[2];(1987); pp. 119-124

[27]. Hilton A. D., Randall C. A., Barber D. J., Shrout T. R.; "TEM studies of $\mathrm{Pb}\left(\mathrm{Mg}_{1 / 3} \quad \mathrm{Nb}_{2 / 3}\right) \mathrm{O}_{3}-\mathrm{PbTiO}_{3}$ Ferroelectric relaxors"; Ferroelectrics; Vol. 93;(1989); pp. 379-386;.

[28]. Shrout T. R., Chang Z. P.Kim, Markgraf S.; "Dielectric behavior of single crystals near the 1$\mathrm{xPb}\left(\mathrm{Mg}_{1 / 3} \mathrm{Nb}_{2 / 3}\right) \mathrm{O}_{3}-\mathrm{x} \quad \mathrm{PbTiO}_{3}$ morphotropic phase boundary"; Ferroelectric letter; Vol. 12; (1990); pp.-63-69.

[29]. Gupta Surya Mohan, Kulkarni Ajit R.; "Dielectric and Microstructure Studies of lead magnesium niobate prepared by partial oxalate route"; Journal of European Ceramics Society; Vol. 16;(1996); pp. 473-480.

[30]. Zhang Y. C., Yang Z., Ye W. N., Lu C. J., Xia L. H.; "Effect of excess $\mathrm{Pb}$ on microstructures and electrical properties of $0.67 \mathrm{~Pb}\left(\mathrm{Mg}_{1 / 3} \mathrm{Nb}_{2 / 3}\right) \mathrm{O}_{3}-0.33 \mathrm{PbTiO}_{3}$ ceramics"; J. Mater. Sci. Mater. Electron; Vol. 22;(2011); pp. 309-314. [31]. Fang Bijun, Jiang Na,Ding Chenlu, Du Qingbo,Ding Jianning; "Decrease of sintering temperature by $\mathrm{CuO}$ doping of the $0.8 \mathrm{~Pb}\left(\mathrm{Mg}_{1 / 3} \mathrm{Nb}_{2 / 3}\right) 0_{3}-0.2 \mathrm{PbTiO}_{3}$ ceramics prepared by reaction -sintering method "; Phys. Status Solidi A; Vol.209, No. 2; (2012); pp. 254-261.

\section{First Step- Preparation of MN/ZN}

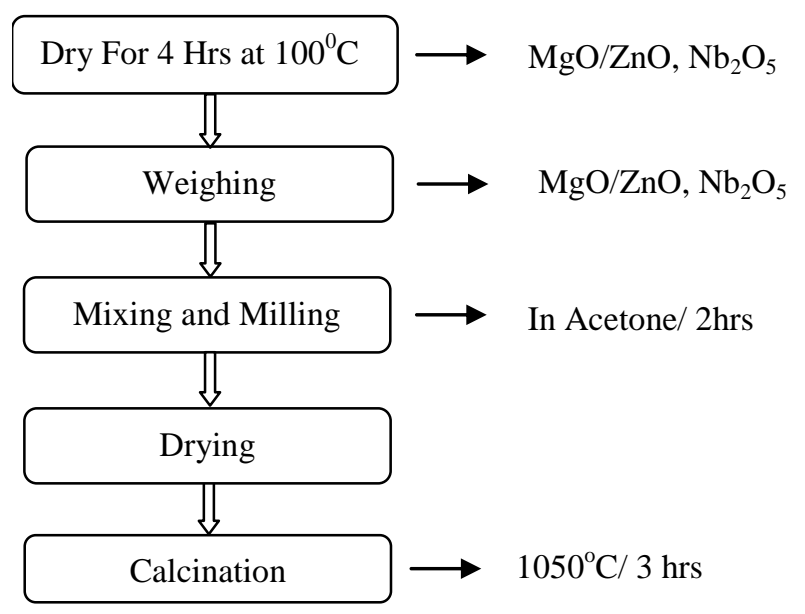

Second Step - Preparation of ceramics of Ternary System

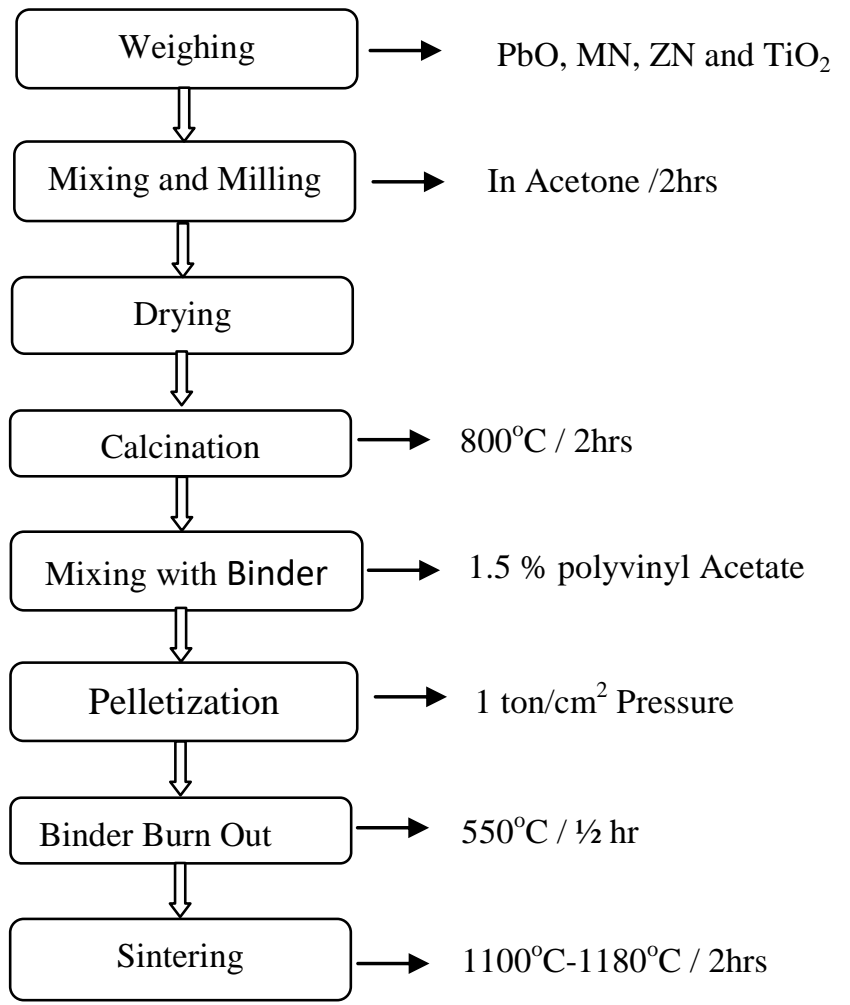

Fig. 1 Flow chart of Material Processing 
Table 1: Designation of sintered ceramics

\begin{tabular}{|c|c|c|c|}
\hline $\begin{array}{l}\text { Composition } \\
\text { 0.7PMN-0.2PT-0.1PZN }\end{array}$ & $\begin{array}{l}\text { Composition } \\
\text { 0.7PMN-0.1PT-0.2PZN }\end{array}$ & $\begin{array}{l}\text { Calcinations temperature } \\
\text { and duration }\end{array}$ & $\begin{array}{l}\text { Sintering } \\
\text { temperature and } \\
\text { duration }\end{array}$ \\
\hline PMZNT1 & PMZNT5 & \multirow{4}{*}{$\mathbf{8 0 0}^{0} \mathrm{C}, 2 \mathrm{hrs}$} & $1100^{0} \mathrm{C}, 2 \mathrm{hrs}$ \\
\hline PMZNT2 & PMZNT6 & & $1150^{\circ} \mathrm{C}, 2 \mathrm{hrs}$ \\
\hline PMZNT3 & PMZNT7 & & $1170^{0} \mathrm{C}, 2 \mathrm{hrs}$ \\
\hline PMZNT4 & PMZNT8 & & $1180^{\circ} \mathrm{C}, 2 \mathrm{hrs}$ \\
\hline
\end{tabular}

Table 2 : Dielectric and Physical properties of sintered ceramics

\begin{tabular}{|l|l|l|l|l|l|l|l|l|l|l|}
\hline Sample & $\begin{array}{l}\varepsilon \text { max } \\
(100 \mathrm{~Hz})\end{array}$ & $\begin{array}{l}\mathrm{Tc} \\
\left({ }^{\circ} \mathrm{C}\right)\end{array}$ & $\begin{array}{l}\tan \delta \\
\text { at Tc }\end{array}$ & $\begin{array}{l}\text { Lattice } \\
\text { Constant } \\
{ }^{\prime} \mathrm{\prime}(\AA)\end{array}$ & $\begin{array}{l}\% \\
\text { pero }\end{array}$ & $\begin{array}{l}\text { Grain } \\
\text { Size }(\mu \mathrm{m})\end{array}$ & $\begin{array}{l}\text { Density } \\
{ }^{\prime} \mathrm{D}\end{array}$ & $\begin{array}{l}\Delta \mathrm{Tc} \\
\left({ }^{0} \mathrm{C}\right)\end{array}$ & $\delta\left({ }^{\circ} \mathrm{C}\right)$ & $\begin{array}{l}\rho \\
\Omega \text {-cm }\end{array}$ \\
\hline PMZNT1 & 15574 & 115 & 0.03 & 3.984 & 100 & $1.6-2.5$ & 82 & 5 & 34 & $2 \times 10^{11}$ \\
\hline PMZNT2 & 16557 & 113 & 0.0303 & 3.987 & 100 & $1.8-3$ & 84 & 4 & 33 & $1.6 \times 10^{11}$ \\
\hline PMZNT3 & 28328 & 108 & 0.0362 & 3.987 & 100 & $3.5-5$ & 90 & 5 & 30 & $1.62 \times 10^{11}$ \\
\hline PMZNT4 & 33409 & 105 & 0.0301 & 3.984 & 100 & $3.5-6.5$ & 95 & 5 & 27 & $4.5 \times 10^{11}$ \\
\hline PMZNT5 & 21541 & 72 & 0.0511 & 3.997 & 100 & $1.8-3$ & 88 & 9 & 33 & $1.38 \times 10^{11}$ \\
\hline PMZNT6 & 24786 & 72 & 0.0395 & 3.987 & 100 & $2.5-4$ & 90 & 7 & 32 & $1.6 \times 10^{11}$ \\
\hline PMZNT7 & 29223 & 69 & 0.0330 & 3.987 & 100 & $4.5-7$ & 95 & 7 & 31 & $1.6 \times 10^{11}$ \\
\hline PMZNT8 & 29911 & 69 & 0.0297 & 3.978 & 100 & $4.5-7.5$ & 95 & 7 & 29 & $4.5 \times 10^{11}$ \\
\hline
\end{tabular}

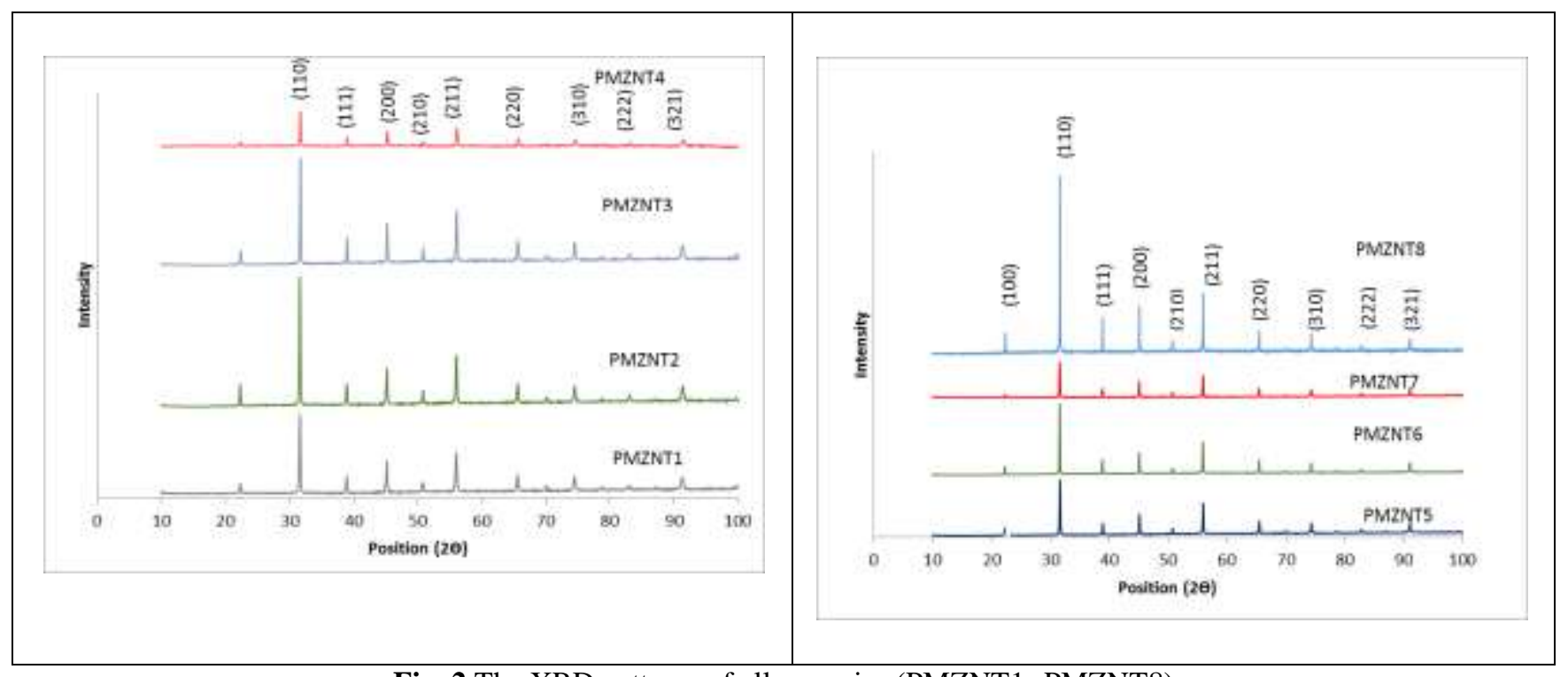

Fig. 2 The XRD patterns of all ceramics (PMZNT1- PMZNT8) 

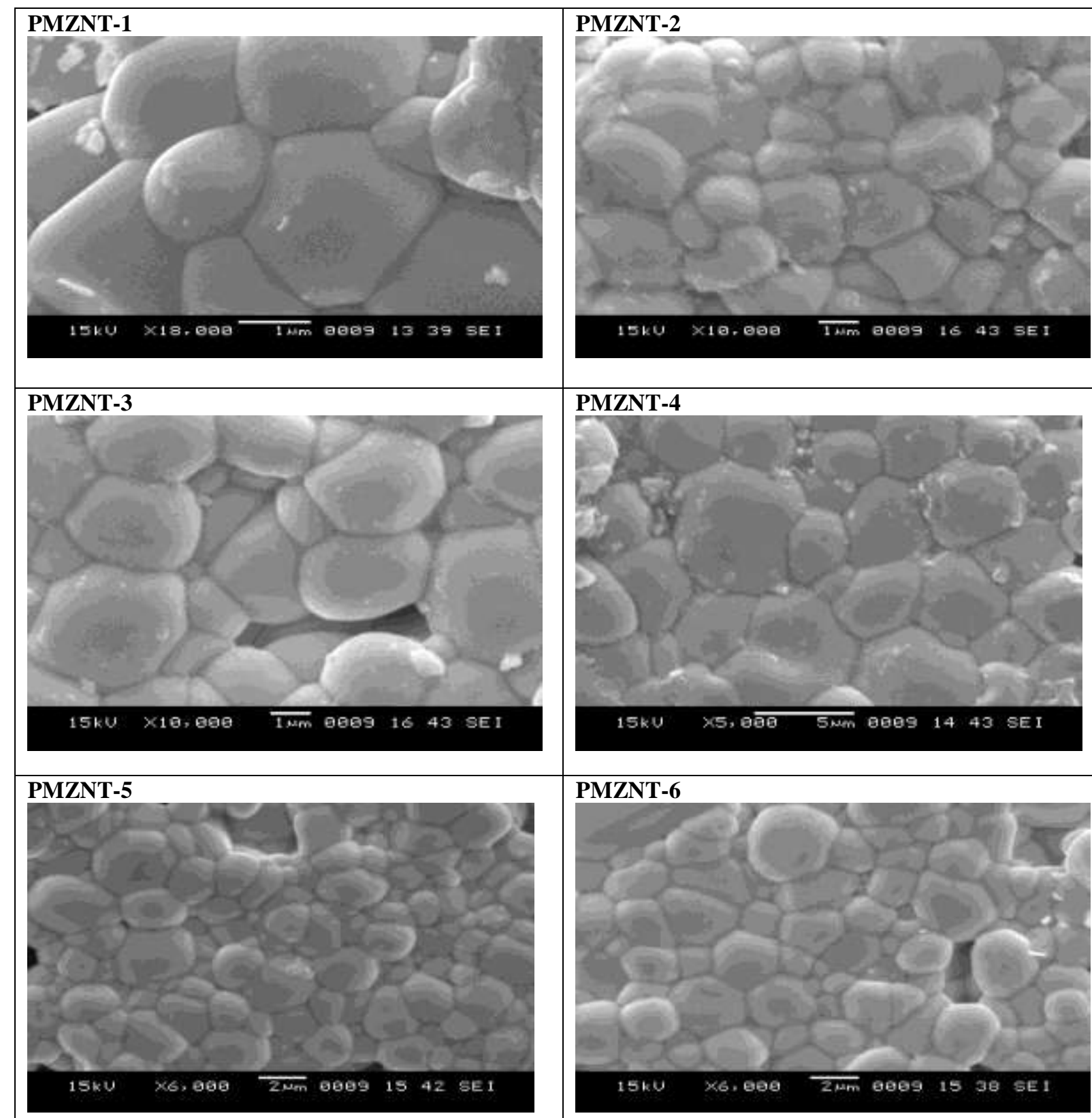

PMZNT-6
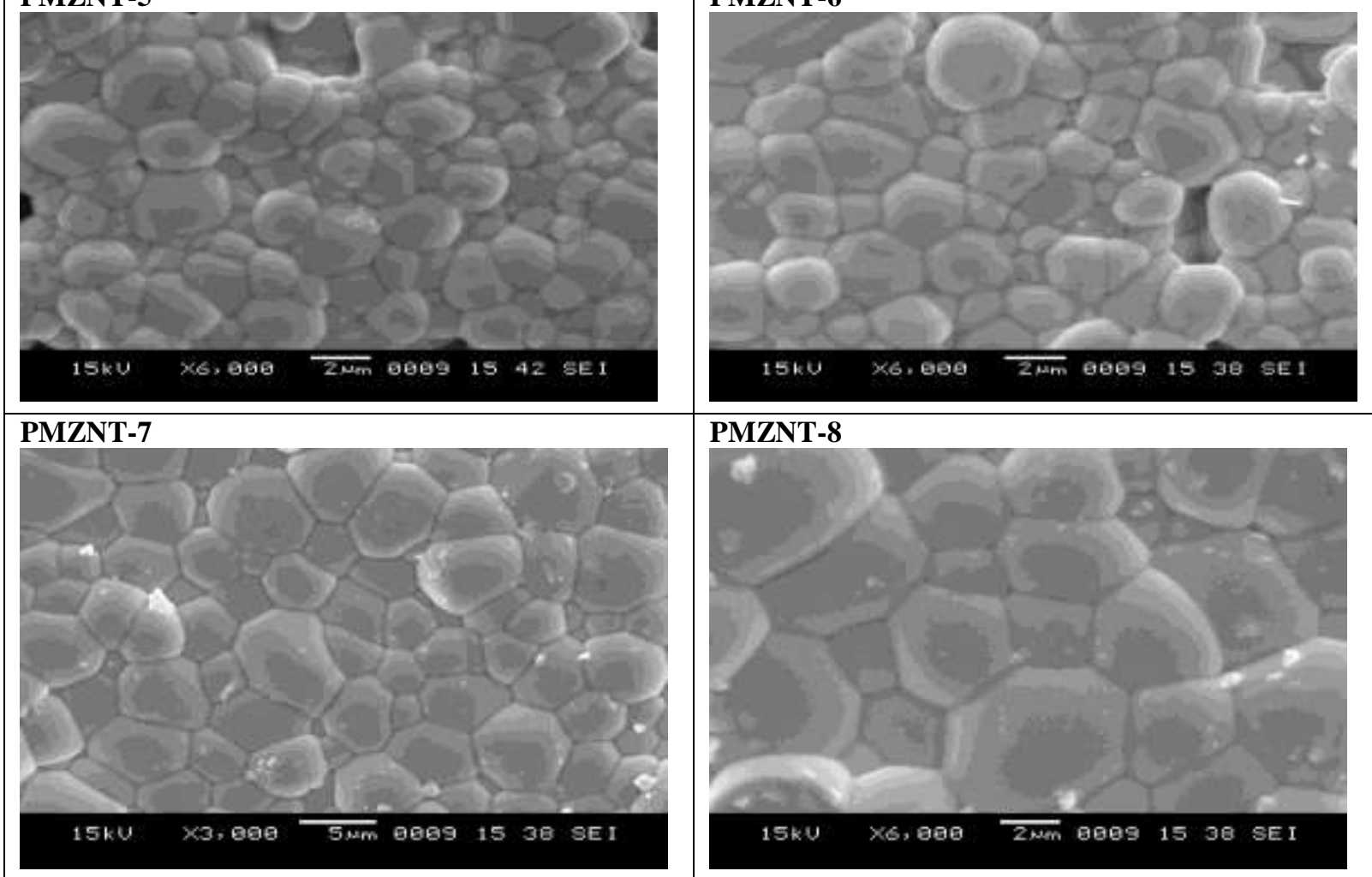

\section{PMZNT-8}

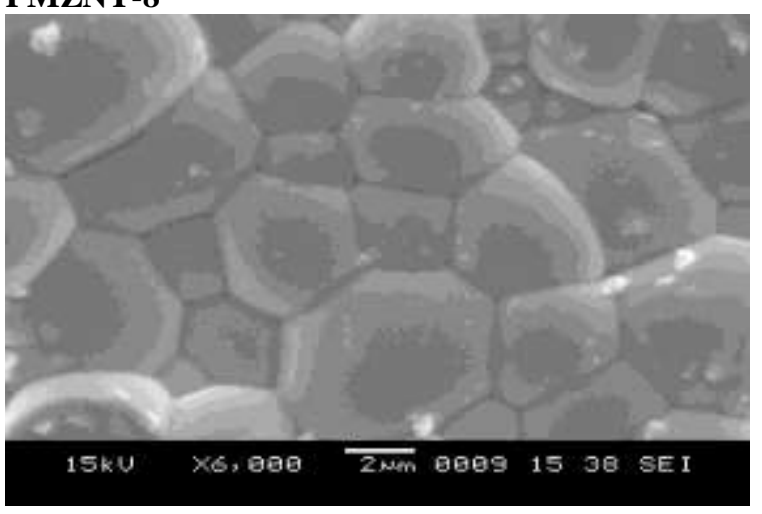

Fig. 3 - Scanning electron micrographs of the sintered ceramics 


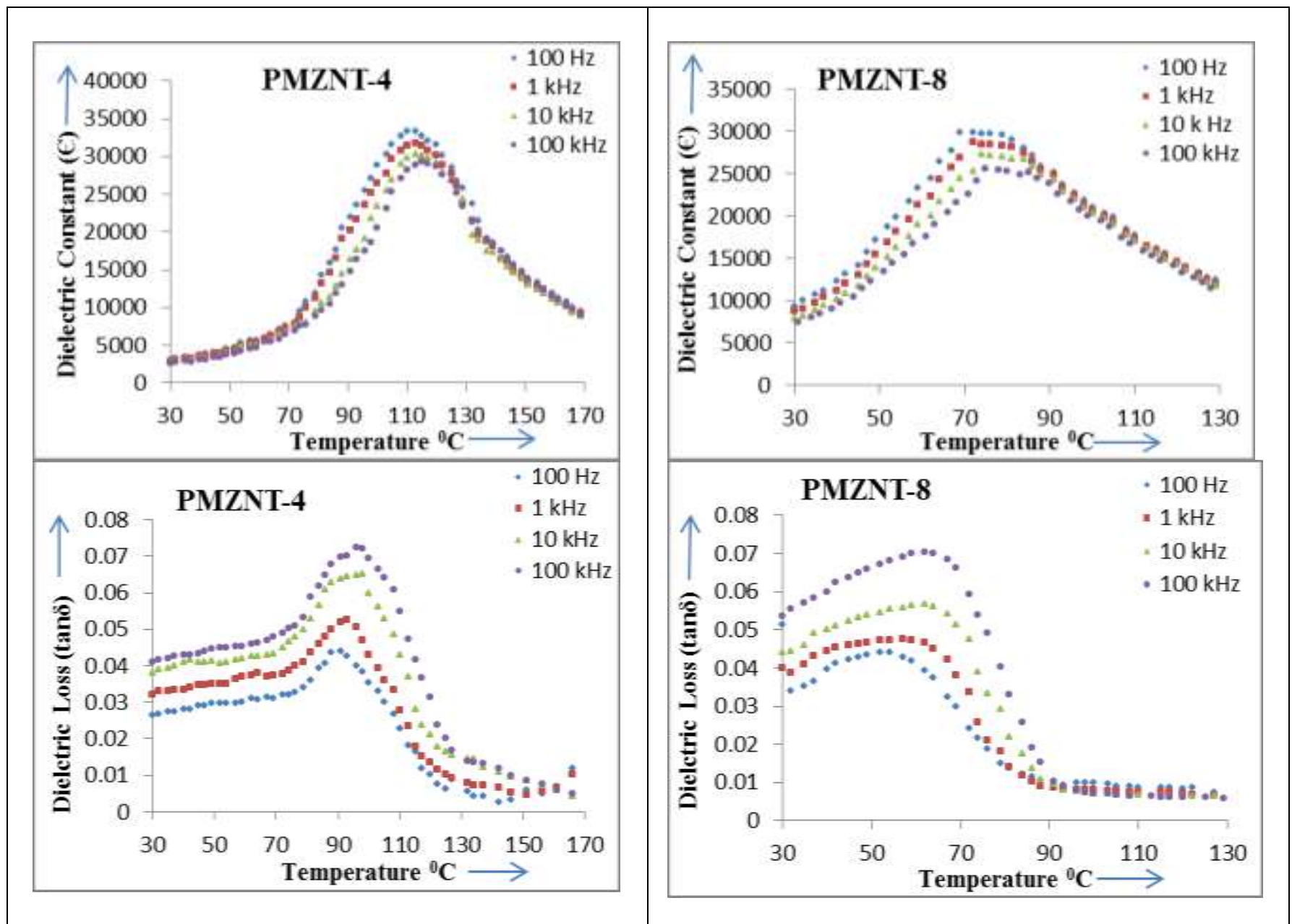

Fig. 4- Graphs of dielectric constant and the loss tangent Vs temperature of ceramics PMZNT4 and PMZNT8.

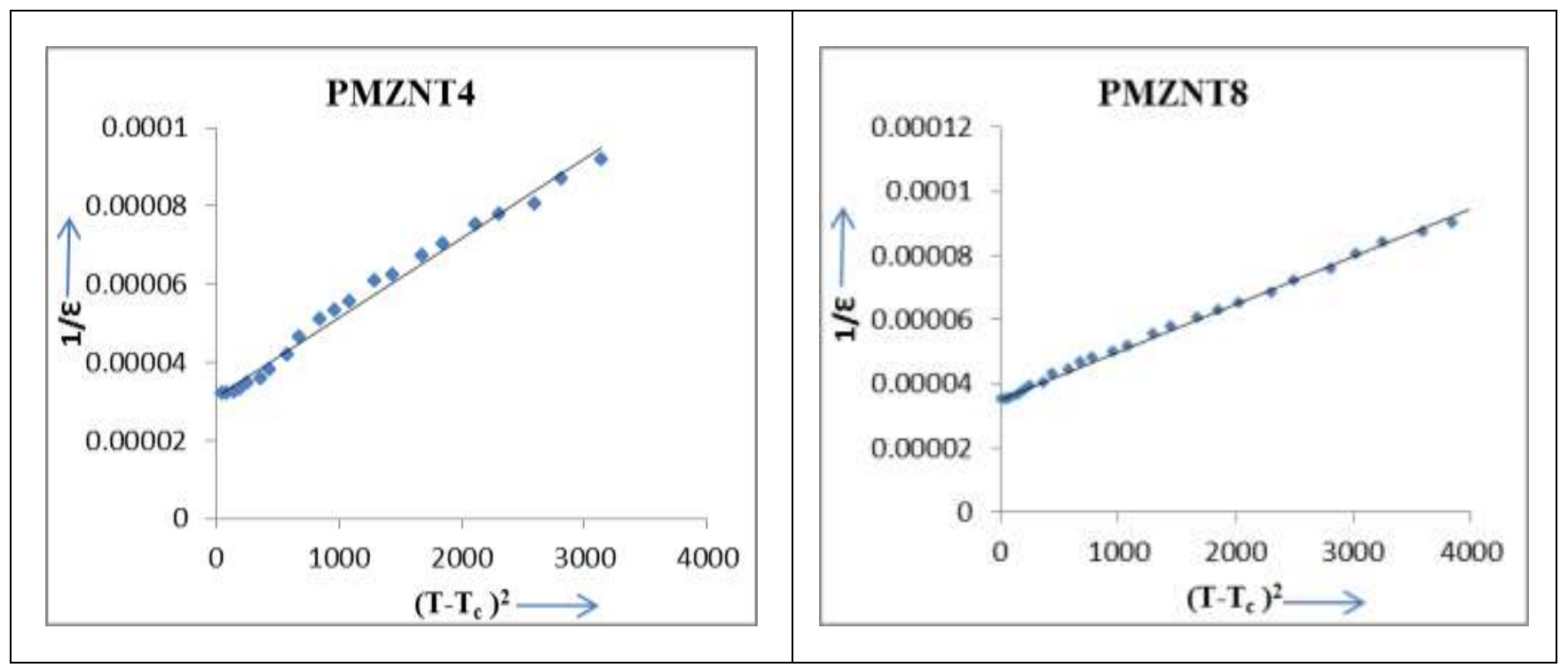

Fig. 5- Quadratic graphs of sintered ceramics 